\section{Sagging economy clips clean tech's wings}

Despite fervent government interest in pursuing renewable energy, worldwide venture-capital investment in the cleantechnology sector has fallen sharply for a second successive quarter, according to data released on 1 April by analysts Cleantech Group and Deloitte.

The sector includes renewable-energy, waste, water and materials technologies as well as the development of less destructive coal- and oil-extraction methods. The influx of venture capital fell from a high of US $\$ 2.6$ billion in the third quarter of 2008 to $\$ 1.7$ billion in last year's final quarter as the depth of the ongoing financial crisis became clear (see chart). This year's first quarter saw a further decline to $\$ 1$ billion,

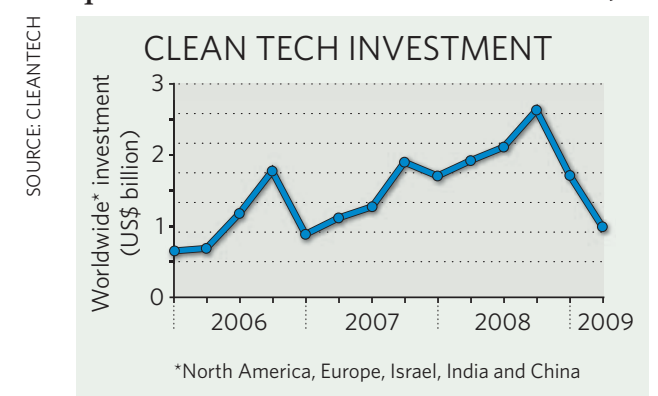

more than one-third of which went into the solar industry.

G20 nations have, however, earmarked an estimated $\$ 400$ billion for green projects as part of their individual economic-stimulus plans (see Nature 458, 562; 2009).

\section{Europe revises animal- research proposals}

Apparently heeding researchers' warnings, politicians last week altered controversial provisions in European draft legislation on animal experiments (see box in Nature 458, 394-395; 2009).

The European Parliament's agriculture committee removed language that would have restricted research on non-human primates to work on "life-threatening or debilitating" conditions. And it stipulated that researchers may now reuse animals in procedures that cause "moderate" - rather than "mild" - pain.

The committee also called for feasibility studies on ending the use of captured wild animals in research, amid concerns about shortages in supply if this move were pushed through too quickly.

Having passed the committee, the draft legislation will be voted on by the full parliament in May before being considered by the European Council and European

Commission. It then heads back to

parliament for a second reading.

For a longer version of this story, see

http://tiny.cc/animals12.

\section{Skeleton transfer to Native Americans put on hold}

An attempt by officials at the University of California, San Diego, to give a pair of nearly 10,000-year-old skeletons to a local Native American tribe has been halted.

This may ultimately save the specimens for scientific study.

Under federal law, bones can be returned to a tribe that can prove 'cultural affiliation' But the skeletons, found on the campus 33 years ago, are too old to be culturally linked to a tribe, say university scientific panels (see Nature 458, 265; 2009).

University chancellor Marye Anne Fox and president Mark Yudof nonetheless requested permission in February from federal officials to offer the Kumeyaay tribe the bones, which have been in dispute for more than two years (Nature 455, 1156-1157; 2008). But Fox has now cancelled that request after Kumeyaay attorneys changed their plea for the bones, seeking university recognition of cultural affiliation. 